The Dusky-footed Wood Rat 


\section{The Dusky-footed}

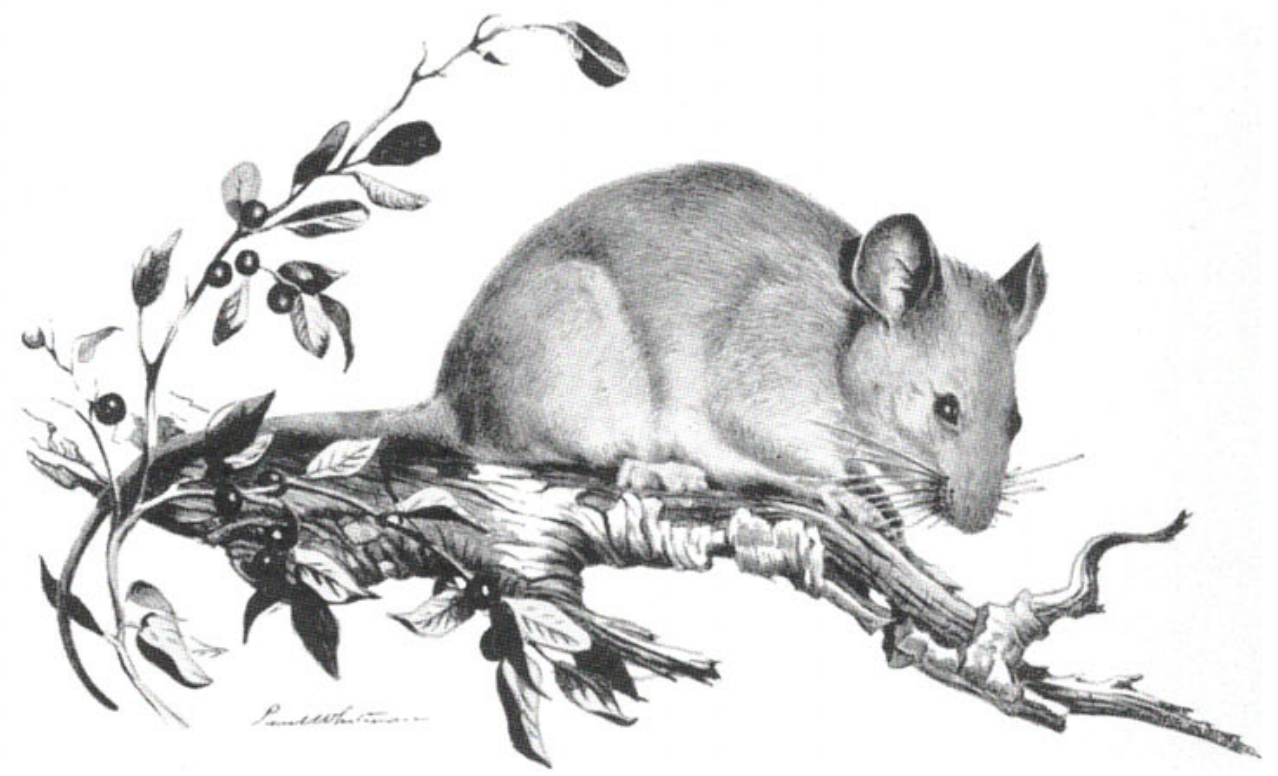




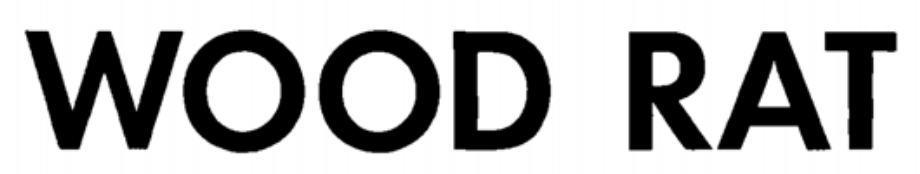

A Record of Observations Made on the Hastings Natural History Reservation

$$
\begin{aligned}
& \text { BY JEAN M. LINSDALE AND } \\
& \text { LLOYD P. TEVIS, JR. }
\end{aligned}
$$

UNIVERSITY OF CALIFORNIA PRESS - Berkeley and Los Angeles · 1951 
UNIVERSITY OF CALIFORNIA PRESS

BERKELEY AND LOS ANGELES, CALIFORNIA

CAMBRIDGE UNIVERSITY PRESS

LONDON, ENGLAND

COPYRIGHT, 1951, BY THE REGENTS OF THE UNIVERSITY OF CALIFORNIA

PRINTED IN THE UNITED STATES OF AMERICA 